\title{
Family Physician's Educational Interview with Patients Helps in Early Recognition of Lower Urinary Tract Symptoms
}

\section{Ana Lesac Brizić (iD \\ Vladimir Mozetič (DD}

Community Health Center of Primorje Gorski Kotar County, Rijeka, Croatia
Correspondence: Ana Lesac Brizić

Tel +3855I 666000

Fax +385 5I 337405

Email ana.lesac.brizic@domzdravlja-pgz.hr
Purpose: Lower urinary tract symptoms (LUTS) can have an etiology outside the lower urinary tract (LUT) and are therefore an important diagnostic indicator for assessing the overall health of a person. However, LUTS is still mainly neglected by primary health care providers as well as by patients. In this study, we assessed the importance of an educational interview (EI) conducted by a GP on the patients' ability to recognize LUTS. We also investigated other factors that affect the recognition of LUTS: subjects' personal educational level, number of LUT symptoms and their bothersome level on a scale 0-10.

Patients and Methods: This cross-sectional study was conducted in Croatia (2018-2020) by interviewing 499 subjects. We compared recognized LUT symptoms before and after the EI and determined whether their number, their bothersome level, or the subjects' personal educational level were associated with LUTS recognition.

Results: EI significantly improved the ability to recognize LUTS ( $p=0.001)$. The number of LUT symptoms and bothersome level in subjects before EI was much greater than the number in subjects after EI $(\mathrm{p}<0.0001$, mean $>4$ and $\mathrm{p}<0.0001$, median $>8$, respectively). Subjects with higher educational level recognized LUTS with fewer symptoms after the EI $(\mathrm{p}<0.01)$, but no difference was observed among subjects who recognized LUTS before the EI.

Conclusion: For subjects to recognize LUTS, their condition had to be severe - more than 4 symptoms and bothersome level $>8 / 10$. Personal educational level had little impact on LUTS recognition. However, an EI proved to be an excellent tool for raising awareness about LUTS and its early recognition.

Keywords: doctor-patient relationship, health promotion, lower urinary tract symptoms, patient education, primary care, quality of care

\section{Introduction}

The term Lower Urinary Tract Symptoms (LUTS) is used for a variety of symptoms associated with lower urinary tract (LUT) dysfunction. In this study, the acronym "LUTS" was used to refer to the condition itself, regardless of the number or nature of symptoms, and the term "LUT symptoms" was used to refer to certain characteristics of one or more symptoms. LUTS can generally be divided into three main categories, depending on the time of onset during the micturition process. ${ }^{1}$ The first group of LUT symptoms are storage symptoms. They manifest while a person stores urine in the bladder and does not try or does not want to urinate (frequency, nocturia, urgency, urinary incontinence, nocturnal 
enuresis and altered bladder sensation). Voiding symptoms appear while a person is urinating or trying to urinate (weak or slow stream, splitting or spraying of the stream, intermittency, hesitancy, straining, terminal dribble). The third group of symptoms, post micturition symptoms (feeling of incomplete emptying and post micturition dribble) are experienced immediately after the person has finished urinating.

The term LUTS was introduced in medical terminology more than 25 years ago, ${ }^{2}$ to replace the old term prostatism, a very important decision due to the misleading former name which led to a conclusion that only men could experience lower urinary tract symptoms, and that these symptoms occur only due to prostate-related reasons. At the time it was used, the misleading name resulted in approximately 10,000 unnecessary prostatectomies per year in Britain. ${ }^{2}$ Furthermore, LUTS should be recognized and treated as early as possible. Although symptoms manifest in the context of LUT, LUTS can be a sign of serious medical conditions with an etiology in other organic systems, ${ }^{3-10}$ or it can serve as base for the development of other diseases, ${ }^{11-14}$ and it significantly decreases the quality of life. ${ }^{15-18}$

However, primary health care, and especially patients, still do not recognize LUTS early enough. Regardless of a large amount of existing literature on LUTS, its causes, clinical representation, and treatments, we know very little regarding the public awareness of its importance as a medical phenomenon. There are several studies on the connection of primary health care providers' level of education on LUTS and their ability to recognize LUTS in patients, as well as on the connection of patients' education on LUTS rehabilitation and their recovery rate. ${ }^{19-21}$ Certain studies have assessed the connection between a person's educational level and the ability to evaluate the severity of LUTS using questionnaires in rural Africa, ${ }^{22}$ or seeking medical help regarding incontinence in women. ${ }^{23}$ Others have noted patients' educational level but have not linked it to the ability to assess the presence or severity of LUTS. ${ }^{24,25}$

The aim of this study is to assess the importance of education in recognizing LUTS through an educational interview (EI) with a physician. To our knowledge, this is the first study to address this topic in such a manner. Our scope is also to identify some of the factors that affect the recognition of LUTS by comparing the number of LUT symptoms, the degree of everyday life disturbance ("bothersome", on a visual analog scale, VAS) and the subjects' personal education level with the number of recognized LUT symptoms, all before and after the EI.

\section{Patients and Methods Subjects}

The research was conducted among voluntary adult respondents in Community health center clinics of Primorje - Gorski kotar County, Croatia, from 2018 to 2020. Since LUTS does not have an ICD code, we studied the general population, without setting exclusion criteria given the (non)existence of any morbidities. There was a total of 12 groups, divided by gender and then by age $(18-30,31-40,41-50,51-60,61-70$ and over 71 years old). We determined a minimal total sample of 384 subjects by the Altman nomogram (test power 0.8). Since non-parametric tests had to be used in the study, an additional $15 \%$ of the original sample size (58 subjects) was added, ${ }^{26}$ resulting in a minimal number of 442 respondents. The research consisted of two parts: the subjects first completed the "educational interview (EI)" and then continued the research process by participating in the "extended research (ER)". The minimum of 442 subjects refers to the number of subjects completing the whole research process (EI and ER).

\section{Methods}

This cross-sectional study was conducted by interviewing respondents who reported to their GP, regardless of the reason. The sample was randomized in a way that at least the first 3 and no more than 5 subjects of a certain gender/ age group were interviewed in each GP's office. EI was not interventional since the educational part of the research served only as a diagnostic tool. The research setup is shown in Figure 1. The subjects first self-reported whether they had any problems urinating (1st detection). Then, they were informed about the clinical manifestations of the researched LUT symptoms (education). After that, it was immediately noted whether subjects recognized some of the mentioned LUT symptoms after the given explanation (2nd detection), and if so - the bothersome level of each reported LUT symptom expressed as a value on a visual analog scale (VAS). The VAS values were defined as 10 being the highest level of bothersome, 1 subjectively most easily tolerated everyday disturbance, and 0 meaning presence of LUTS, but without any subjective disturbances. The total number of LUT symptoms per person and the value of VAS scores for each LUT symptom were 


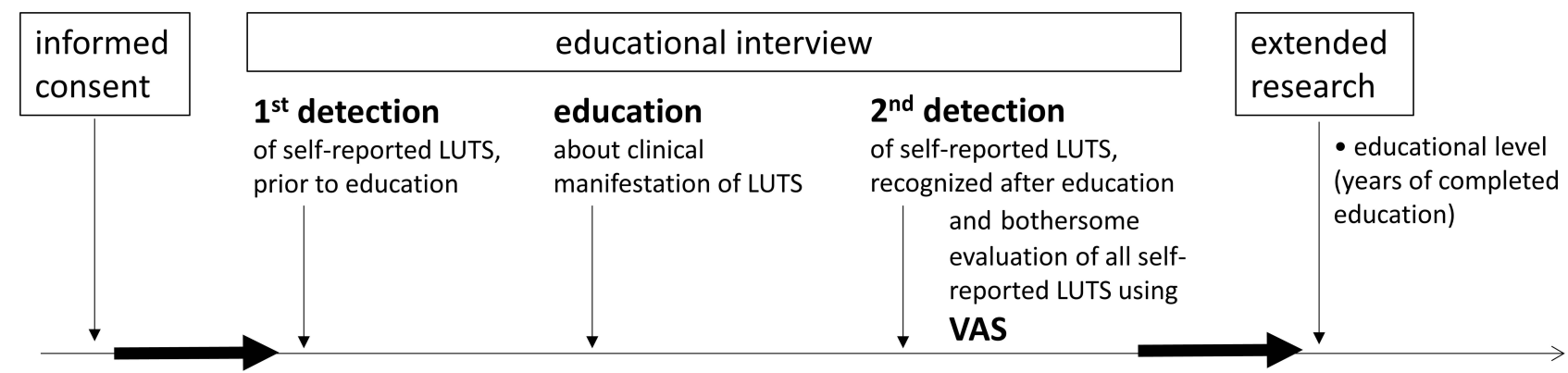

Figure I The research setup. After stratified random sampling, total of 499 primary care patients signed the informed consent and participated in educational interview: first they self-reported any lower urinary tract symptoms, following the education about the clinical manifestations of investigated symptoms. After education, subjects were able to report if they recognized any more of the lower urinary tract symptoms, as well as evaluated bothersome level of each reported symptom.

determined and compared across age-gender groups. We assessed the connection between the number of LUT symptoms and the VAS scores' value, with the recognition of LUTS presence with or without EI.

\section{Ethical Aspects}

All participants read the Informed consent and signed a Consent to participate in the research. The research was conducted with the written consent of the clinical practices' team leaders, and with the approval of the Ethics Committee of the Community health center of Primorje-Gorski Kotar County (Croatia) and of the University of Rijeka, Faculty of Medicine (Croatia). Compliance with bioethical standards, basic bioethical principles, as well as those derived from them, in accordance with the Nuremberg Code, the latest revision of Helsinki declarations, and other relevant documents were ensured in the research.

\section{Statistics}

The data were processed statistically and graphically displayed using a computer software GraphPad Prism 8.0.0 for Windows (GraphPad Software, San Diego, California USA). We used descriptive statistics, with percentages and medians with interquartile range (IQR) to describe the percentage of population affected by LUTS, the distribution of the number of LUT symptoms and its VAS values, respectively, as well as the mean value of LUT symptoms per person. The normality of data distribution was tested with the Kolmogorov-Smirnov test. The McNemar test with Yates correction was used to determine the association of EI with LUTS recognition. The number of LUT symptoms per person and VAS scoring results in subjects who reported LUTS before and after the EI was compared by the Kruskal-Wallis test. The "bothersome" is shown in numbers ranging from 0 to 10 on the ordinal scale. The Kruskal-Wallis test and the Mann-Whitney $U$-test for post hoc analysis were used to analyze the association between the subjects' personal education level and LUTS recognition. $P<0.05$ was considered statistically significant.

\section{Results}

\section{Participant Characteristics}

The total number of participants was $499(\mathrm{~N}$ (male) $=241$, $\mathrm{N}$ (female) $=258$ ), all of whom completed the EI part of the survey, and 444 of them completed the ER part of the survey (37 participants per age/gender group). The characteristics of the study participants are described in the methods-subjects section.

\section{Primary Health-Care Patients are Highly Unaware of Their Lower Urinary Tract Symptoms, and an Educational Interview with Their Health Care Provider Significantly Improves Their Recognition of LUTS}

A total of 499 patients who visited their GP, regardless of the reason, were asked to self-assess whether they had any problems urinating. The results are shown in the Figure 2. Then, the EI with each subject was performed, where the clinical manifestation of the 11 LUT symptoms was described and explained. If, during the EI, subjects recognized any of the LUT symptoms that they had not previously recognized or mentioned, the information was noted. As shown in Figure 2, subjects reported significantly more LUT symptoms after EI (McNemar test with Yates correction, $\chi^{2}(1, \mathrm{~N}=241)=92.01, p<0.0001$ and $\chi^{2}$ $(1, \mathrm{~N}=258)=119.01, p<0.0001$ for men and women, respectively). 


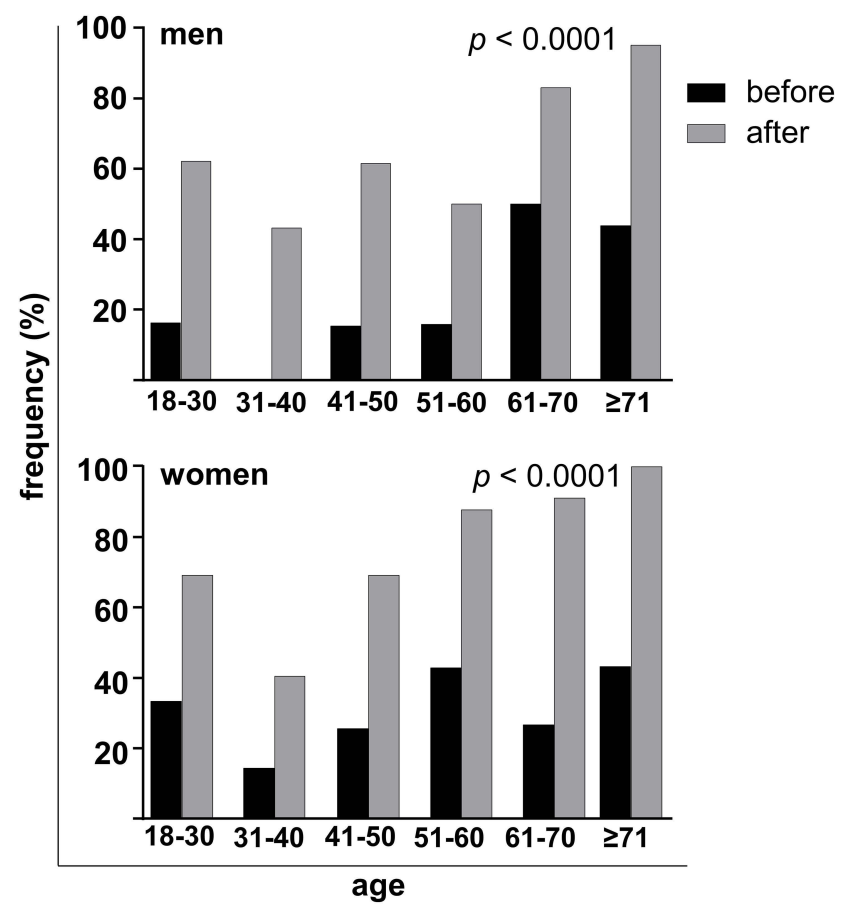

Figure 2 The impact of the educational interview on the recognition of LUTS. The percentages of subjects who reported the presence of urinary problems before and after the educational interview are shown.

\section{The Higher Number of LUT Symptoms is Associated with Better Condition Recognition}

Since there were subjects who recognized the presence of LUTS even before the educational interview, we tried to explore possible factors that could facilitate the recognition and understanding of the condition. We hypothesized that a person would notice LUTS more easily if he or she had more symptoms. Indeed, as seen in Figure 3, subjects who recognized the presence of LUTS before EI had a higher number of LUT symptoms than those who recognized the presence of LUTS only after EI (Kruskal-Wallis test, $p<0.0001)$. On average, a person that can recognize the condition has already developed at least 4 LUT symptoms.

\section{Higher Values of VAS Scores Attributed to LUT Symptoms are Associated with Better Condition Recognition}

We also hypothesized that if a particular LUT symptom was more bothersome (higher VAS score), it would be

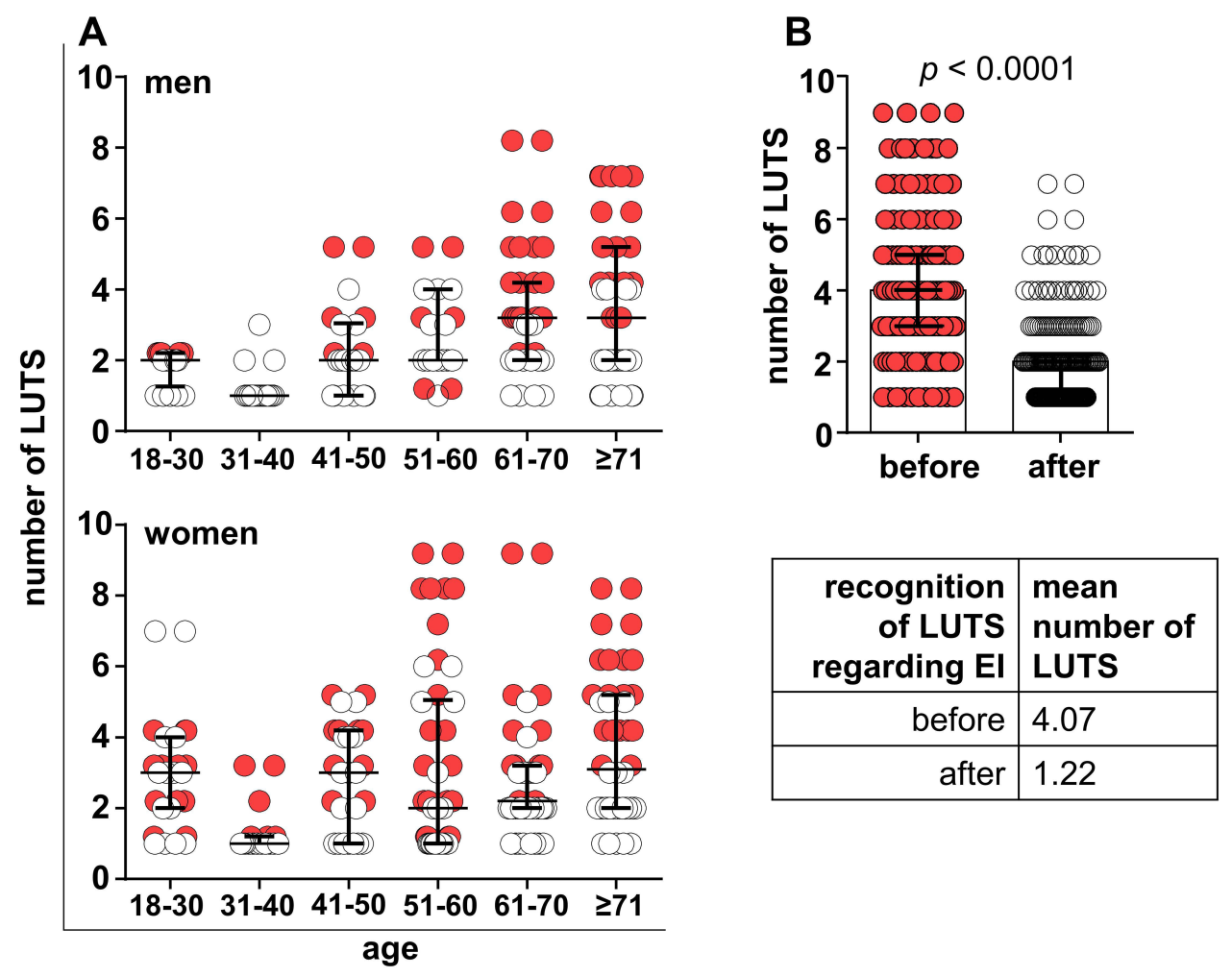

Figure 3 The impact of the number of urinary problems on the recognition of LUTS. (A) Individual results of the subjects: the results of the subjects who recognized and reported LUTS before El are shown in red. The results of the subjects who recognized the presence of LUTS only after El are shown in white. (B) Comparison of the number of recognized and reported LUTS before and after the El. Medians with IQR, and mean value of number of LUT symptoms in the table are shown. 


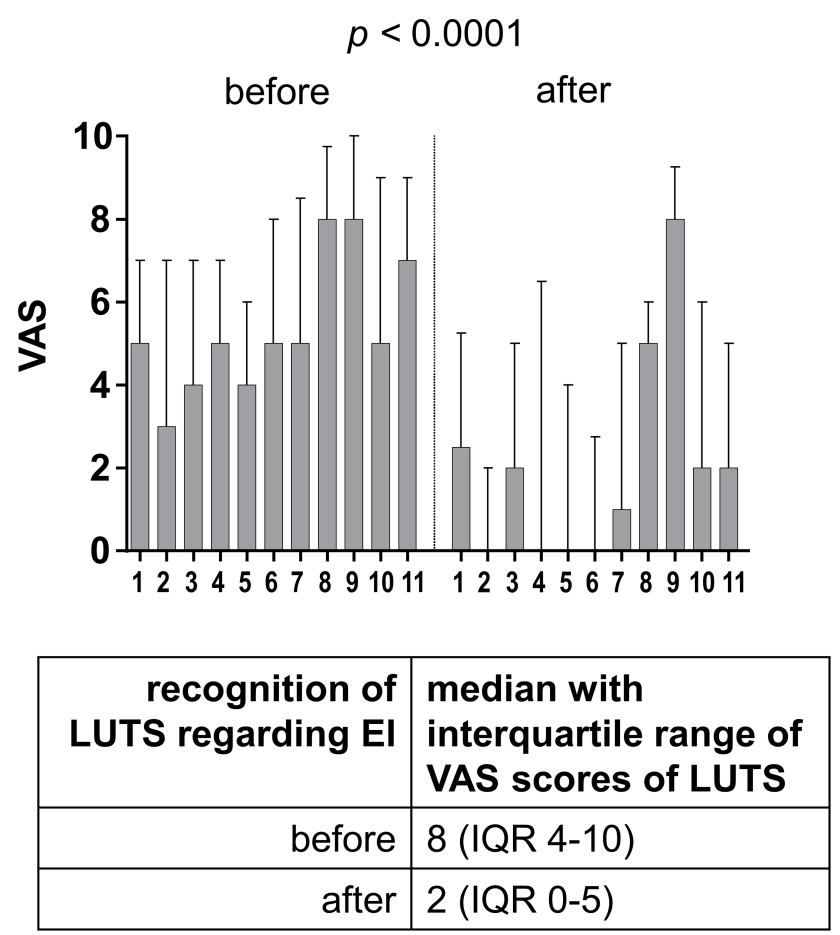

Figure 4 The association between the VAS scores attributed to different urinary problems on the recognition of LUTS. VAS scores of different LUT symptoms recognized before El and VAS scores of LUT symptoms recognized only after El are shown. The medians with IQR are shown. Each column represents one LUT symptom: I) hesitancy, 2) weak stream, 3) feeling of incomplete emptying of the bladder, 4) straining, 5) frequency, 6) nocturia, 7) urgency, 8) urgent incontinency, 9) painful urination, burning, 10) terminal dribble, II) incontinency.

easier for a person to recognize it. We compared the highest bothersome reported LUT symptom VAS scores, with the time of reporting the symptom (before or after EI). Figure 4 shows that subjects who recognized LUTS before EI had higher VAS score values than those who recognized and reported LUTS only after EI (Kruskal-Wallis test, $p<0.0001)$. Surprisingly, the median VAS score value had to be greater than 8 (IQR 4-10) for a person to recognize and report LUTS. This data also supports the assumption that EI facilitates the recognition of LUTS, since subjects recognized their LUT symptoms despite the low VAS scores (median $=2$, IQR 0-5).

\section{Personal Educational Level Does Not Play a Major Role in Recognizing LUTS}

The subjects were divided into three groups, depending on their personal educational level expressed as years of completed education. According to Croatian standards, these groups are as follows: without formal education or completed primary school (duration 8 years), high school education level (11 or 12 years) and graduated from college or higher (at least 15 years of education). Data on subjects' personal education levels were collected during the second phase of the research (ER), which included 444 participants. Subjects with higher education were able to recognize urinary problems while still having fewer symptoms than less educated subjects, but only after EI, as seen in Figure 5 (Kruskal-Wallis test, $p=0.0691$ and $p<0.0001$, for "before EI" and "after EI" group, respectively. The results of post hoc Mann-Whitney analysis are noted with an asterisk sign in Figure 5). LUTS recognition in regard of VAS scores was not associated with personal educational level (Kruskal-Wallis test, $p=0.8498$ and $p=0.1138$, for "before EI" and "after EI" group, respectively).

\section{Discussion}

Several studies have already addressed the general public's poor awareness of LUTS' importance, as well as the awareness of GPs. ${ }^{19-21,23,32,34}$ To our knowledge, we are the first to conduct a study on the importance of an educational interview with a GP on the recognition of LUTS, and the first to look for LUTS in the general population who were unaware of their condition.

Surprisingly, a high frequency of studied individuals was not aware of their LUTS. The self-reported prevalence of LUT symptoms before EI was not consistent with the results of similar studies. ${ }^{25,27-34}$ For example, the male population over 41 and 51 years of age had lower prevalence of LUTS than expected. Moreover, the male population aged between 31 and 40 did not report the presence of any LUT symptom at all. Furthermore, in the female population, older women did not have higher frequencies of LUTS than the younger ones, as would be expected. ${ }^{25,31,33,34}$ Our study showed that a person needed to have at least 4 symptoms to be aware of LUTS. However, it is important to note that these patients did not seek medical help due to LUTS, but only reported the symptom upon enrolment into study.

VAS scores of bothersome level attributed to LUT symptoms recognized before EI were very high - half of the respondents had a VAS higher than 4, with a median of 8 . The scale included a value of 0 (a person recognized the presence of certain LUT symptom, but the presence of that symptom had no impact on everyday life and does not bother the subject at all), which was also used during the calculation of the median, mathematically lowering the median value.

From an informal conversation with the participants after EI, we learned that they consider most symptoms to 


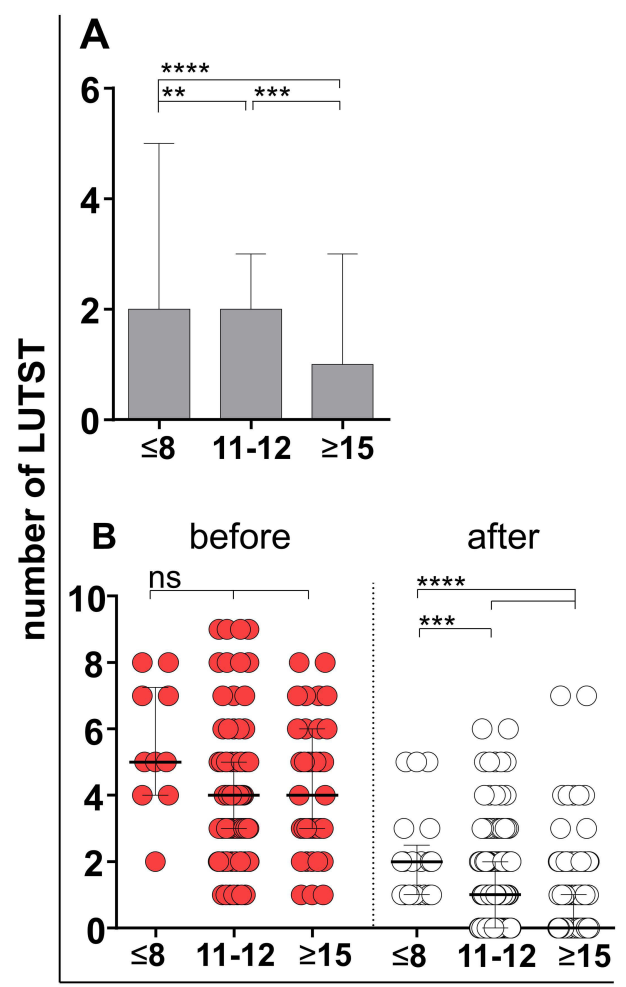

years of completed education

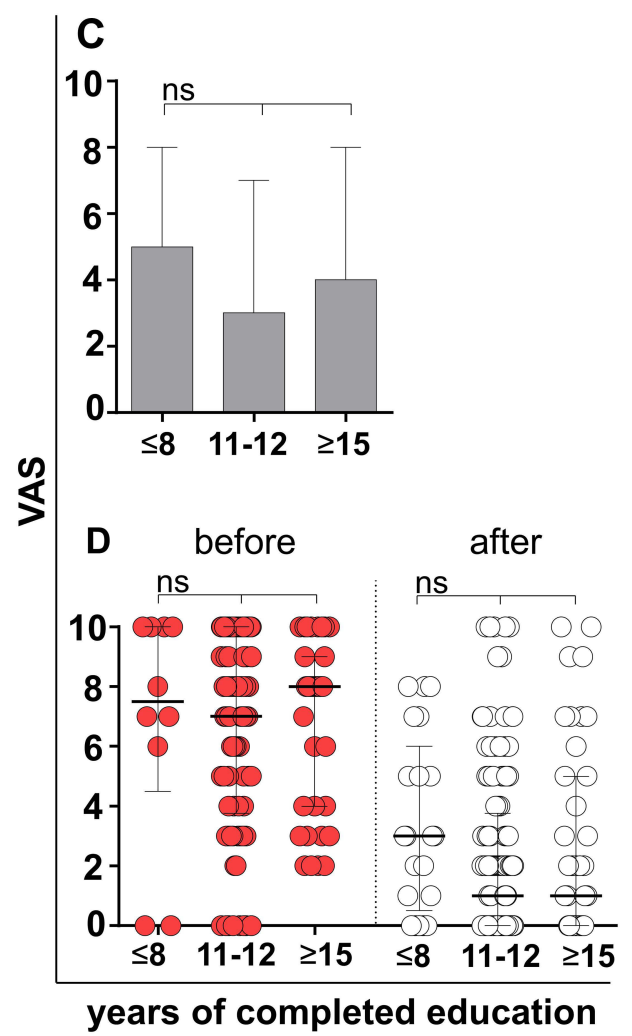

Figure 5 The impact of subjects' personal education level on the recognition of LUTS. The numbers of LUT symptoms that the subjects recognized and reported, depending on their educational level (A), and the VAS scores shown as medians with IQE (C) are shown. (B and D) Comparison of the numbers of LUT symptoms and their VAS scores in regard to subjects' personal education level between the subjects that reported LUTS before and after El. The results of post hoc analysis by Mann-Whitney $U$-test for (A) $* * * * p<0.0001, * * * p=0.0009, * * p=0.0096$, and for $(\mathbf{B}) * * * * p<0.0001$ and $* * * p=0.0080$.

be normal for their age, or that they do not need to pay attention to them. Very few people were aware that LUTS might not have a cause solely in the urinary tract and can be a sign of a plethora of other diseases, or that symptoms may worsen over time and greatly impair health-related quality of life.

The study showed that subjects' personal education level did not play a major role in recognizing LUTS. This was expected, as formal education does not teach the general population specifically about this matter, or any health-related matter in general. Nevertheless, given the results of EI, we believe that better health education at the basic levels of education would be of great benefit to future generations.

The results presented in this study have to be seen in light of some limitations. The sample size was statistically determined so that the number of subjects was sufficient and representative for Primorje - Gorski kotar County. However, although we do not expect differences in the rest of Croatia, a larger sample covering the entire population of the country would give a better insight into the situation.

\section{Conclusion}

Our results show that an educational interview with a general practitioner significantly helps patients in recognition of lower urinary tract symptoms. After educational interview, subjects were able to recognize lower urinary tract symptoms while still having fewer symptoms and relatively low bothersome levels. The overall effect of the study, although not shown in figures, was that many subjects sought the help of a general practitioner, or a urologist, where needed, for symptoms that had been neglected until educational interview.

\section{Abbreviations}

EI, educational interview; ER, extended research; GP, general practitioner; ICD, International Classification of Diseases; IQR, interquartile range; LUT, lower urinary tract; LUTS, lower urinary tract symptoms; VAS, visual analog scale.

\section{Ethics Statement}

This study was approved by the Ethics Committee of the Community health center, Primorje - Gorski kotar County 
(Croatia) and the Medical Faculty of the University of Rijeka (Croatia). All GPs to whose clinical practices the participants belonged to give their written consent, and all the participants signed informed consent.

\section{Consent for Publication}

All authors have read the final manuscript and approve of the publication of its content.

\section{Acknowledgments}

We thank all the GPs in whose offices we conducted the study and all the participants.

\section{Author Contributions}

All authors made a significant contribution to the work reported, whether that is in the conception, study design, execution, acquisition of data, analysis and interpretation, or in all these areas; took part in drafting, revising or critically reviewing the article; gave final approval of the version to be published; have agreed on the journal to which the article has been submitted; and agree to be accountable for all aspects of the work.

\section{Funding}

No funding was received for this work.

\section{Disclosure}

The authors report no conflicts of interest in this work.

\section{References}

1. Abrams P, Cardozo L, Fall M, et al. The standardisation of terminology in lower urinary tract function: report from the standardisation sub-committee of the International Continence Society. Urology. 2003;61(1):37-49. doi:10.1016/S0090-4295(02)02243-4

2. Abrams P. New words for old: lower urinary tract symptoms for "prostatism". BMJ. 1994;308(6934):929-930. doi:10.1136/bmj.308. 6934.929

3. Pacini G, Paolino S, Trombetta A, et al. Lower urinary tract symptoms in systemic sclerosis: a detailed investigation. Rheumatology. 2020;59 (6):1315-1324. doi:10.1185/03007995.2014.934794

4. Shimizu A, Sakakibara R, Takahashi O, Tateno F, Aiba Y. Bladder overactivity and post-void residual: which relates more to systemic atherosclerotic markers? Auton Neurosci. 2020;223:102600. doi:10. 1016/j.autneu.2019.102600

5. Pimentel Torres J, Morais N, Cordeiro A, Lima E. Abscess originating from osteomyelitis as a cause of lower urinary tract symptoms (LUTS) and acute urinary retention. BMJ Case Rep. 2018;2018. doi:10.1136/ bcr-2018-224559.

6. Kogan MI, Belousov II, Ibishev HS, et al. [Association of lower urinary tract symptoms and testosterone deficiency in men with type 2 diabetes]. Urologiia. 2016;1(6):22-26. Russian.

7. Moussa M, Papatsoris A, Chakra MA, Fares Y, Dellis A. Lower urinary tract dysfunction in common neurological diseases. Turk J Urol. 2020;46(Supp. 1):S70-S78. doi:10.5152/tud.2020.20092
8. Geynisman-Tan J, Helmuth M, Smith AR, et al. Prevalence of childhood trauma and its association with lower urinary tract symptoms in women and men in the LURN study. Neurourol Urodyn. 2021;40 (2):632-641. doi:10.1002/nau.24613

9. Felde G, Engeland A, Hunskaar S. Urinary incontinence associated with anxiety and depression: the impact of psychotropic drugs in a cross-sectional study from the Norwegian HUNT study. $B M C$ Psychiatry. 2020;20(1):521. doi:10.1186/s12888-020-02922-4

10. Lazar JM, Chobufo MD, Weiss JP, et al. Nocturia is associated with high atherosclerotic cardiovascular disease risk in women: results from the national health and nutrition examination survey. J Community Health. 2021;46(4):854-860. doi:10.1007/s10900-02100962-9

11. Cheng S, Lin D, Hu T, et al. Association of urinary incontinence and depression or anxiety: a meta-analysis. J Int Med Res. 2020;48 (6):300060520931348. doi:10.1177/0300060520931348

12. Matsuda Y, Kobayashi K, Fukuta F, et al. Which happens earlier, lower urinary tract symptoms or erectile dysfunction? Sex Med. 2021;9(2):100275. doi:10.1016/j.esxm.2020.10.003

13. Burzyński B, Kwiatkowska K, Sołtysiak-Gibała Z, et al. Impact of stress urinary incontinence on female sexual activity. Eur Rev Med Pharmacol Sci. 2021;25(2):643-653. doi:10.26355/eurrev_2021 01_24622

14. Eray \$, Tekcan D, Baran Y. More anxious or more shy? Examining the social anxiety levels of adolescents with primary enuresis nocturna: a controlled study. J Pediatr Urol. 2019;15(4):343.e1-343.e5. doi:10.1016/j.jpurol.2019.04.002

15. Liao L, Chuang YC, Liu SP, et al. Effect of lower urinary tract symptoms on the quality of life and sexual function of males in China, Taiwan, and South Korea: subgroup analysis of a cross-sectional, population-based study. Low Urin Tract Symptoms. 2019;11(2):O78-O84. doi:10.1111/luts.12220

16. Kupelian V, Wei JT, O'Leary MP, et al. Prevalence of lower urinary tract symptoms and effect on quality of life in a racially and ethnically diverse random sample: the Boston Area Community Health (BACH) Survey. Arch Intern Med. 2006;166(21):2381-2387. doi:10.1001/archinte.166.21.2381

17. Coyne KS, Wein AJ, Tubaro A, et al. The burden of lower urinary tract symptoms: evaluating the effect of LUTS on health-related quality of life, anxiety and depression: epiLUTS. BJU Int. 2009;103 (Suppl 3):4-11. doi:10.1111/j.1464-410X.2009.08371.x

18. Coyne KS, Sexton CC, Irwin DE, Kopp ZS, Kelleher CJ, Milsom I. The impact of overactive bladder, incontinence and other lower urinary tract symptoms on quality of life, work productivity, sexuality and emotional well-being in men and women: results from the EPIC study. BJU Int. 2008;101(11):1388-1395. doi:10.1111/j.1464410X.2008.07601.x

19. Faubion SS, Shuster LT, Bharucha AE. Recognition and management of nonrelaxing pelvic floor dysfunction. Mayo Clin Proc. 2012;87 (2):187-193. doi:10.1016/j.mayocp.2011.09.004

20. Blasco P, Valdivia MI, Oña MR, Roset M, Mora AM, Hernández M. Clinical characteristics, beliefs, and coping strategies among older patients with overactive bladder. Neurourol Urodyn. 2017;36 (3):774-779. doi:10.1002/nau.23022

21. Nassir AM, Baazeem A, Saada H, et al. Urological knowledge among primary health care physicians in Saudi Arabia. Saudi Med J. 2019;40(5):483-489. doi:10.15537/smj.2019.5.24080

22. Stothers L, Macnab A, Bajunirwe F, Mutabazi S, Lobatt C. Comprehension and construct validity of the Visual Prostate Symptom Score (VPSS) by men with obstructive lower urinary tract symptoms in rural Africa. Can Urol Assoc J. 2017;11(11): E405-E408. doi:10.5489/cuaj.4589

23. Vethanayagam N, Orrell A, Dahlberg L, et al. Understanding help-seeking in older people with urinary incontinence: an interview study. Health Soc Care Community. 2017;25(3):1061-1069. doi:10. 1111/hsc.12406 
24. Chapple C, Castro-Diaz D, Chuang YC, et al. Prevalence of Lower urinary tract symptoms in China, Taiwan, and South Korea: results from a cross-sectional, population-based study. Adv Ther. 2017;34 (8):1953-1965. doi:10.1007/s12325-017-0577-9

25. Coyne KS, Sexton CC, Thompson CL, et al. The prevalence of lower urinary tract symptoms (LUTS) in the USA, the UK and Sweden: results from the Epidemiology of LUTS (EpiLUTS) study. BJU Int. 2009;104(3):352-360. doi:10.1111/j.1464-410X.2009.08427.x

26. Lehmann EL, D'Abrera HJM. Nonparametrics: Statistical Methods Based on Ranks. Rev 1st ed. Springer; 2006:xvi, 463

27. Milsom I, Abrams P, Cardozo L, Roberts RG, Thüroff J, Wein AJ. How widespread are the symptoms of an overactive bladder and how are they managed? A population-based prevalence study. BJU Int. 2001;87(9):760-766. doi:10.1046/j.1464-410x.2001.02228.x

28. Irwin DE, Milsom I, Hunskaar S, et al. Population-based survey of urinary incontinence, overactive bladder, and other lower urinary tract symptoms in five countries: results of the EPIC study. Eur Urol. 2006;50 (6):1306-14;discussion 1314-5. doi:10.1016/j.eururo.2006.09.019

29. Kogan MI, Zachoval R, Ozyurt C, Schäfer T, Christensen N. Epidemiology and impact of urinary incontinence, overactive bladder, and other lower urinary tract symptoms: results of the EPIC survey in Russia, Czech Republic, and Turkey. Curr Med Res Opin. 2014;30(10):2119-2130. doi:10.1185/03007995.2014.934794
30. Shamliyan TA, Wyman JF, Ping R, Wilt TJ, Kane RL. Male urinary incontinence: prevalence, risk factors, and preventive interventions. Rev Urol. 2009;11(3):145-165.

31. Yoo TK, Lee KS, Sumarsono B, et al. The prevalence of lower urinary tract symptoms in population aged 40 years or over, in South Korea. Investig Clin Urol. 2018;59(3):166-176. doi:10.4111/ icu.2018.59.3.166

32. Wang JY, Liao L, Liu M, Sumarsono B, Cong M. Epidemiology of lower urinary tract symptoms in a cross-sectional, population-based study: the status in China. Medicine. 2018;97(34):e11554. doi:10.1097/MD.0000000000011554

33. Przydacz M, Golabek T, Dudek P, Lipinski M, Chlosta P. Prevalence and bother of lower urinary tract symptoms and overactive bladder in Poland, an Eastern European Study. Sci Rep. 2020;10(1):19819. doi: $10.1038 / \mathrm{s} 41598-020-76846-0$

34. Liu SP, Chuang YC, Sumarsono B, Chang HC. The prevalence and bother of lower urinary tract symptoms in men and women aged 40 years or over in Taiwan. J Formos Med Assoc. 2019;118(1 Pt 1):170-178. doi:10.1016/j.jfma.2018.03.006

\section{Publish your work in this journal}

The International Journal of General Medicine is an international, peer-reviewed open-access journal that focuses on general and internal medicine, pathogenesis, epidemiology, diagnosis, monitoring and treatment protocols. The journal is characterized by the rapid reporting of reviews, original research and clinical studies across all disease areas. The manuscript management system is completely online and includes a very quick and fair peer-review system, which is all easy to use. Visit http://www.dovepress.com/ testimonials.php to read real quotes from published authors. 